IMPORTANCE OF PATENT AND INNOVATION IN EDUCATIONAL INSTITUTIONS

Mário Al Kassiri ${ }^{1}$, Tatiana Čorejová ${ }^{2}$

\begin{abstract}
This articles discusses the importance of converting knowledge into realizable output, which can subsequently be patented. Patenting, in itself, is already the result of a completed and difficult process. The importance of patenting is not only advantageous for the author patent, but also for the whole society and knowledge-based economy. In this article, we explain not only the effect of patenting on the economy as a whole, along with its advantages, but also possible acceleration in process of patenting. Universities rely on the important aspect of innovation and patenting, whereas innovation and patenting alone support the economic growth. Lack of projects covering patenting process may cause less outputs of innovation. Projects which support the development of innovation and start-ups have big potential in reducing unemployment and increasing the motivation of new foreign investors.
\end{abstract}

JEL Classification Numbers: O12, O31, O10, DOI: http://dx.doi.org/10.12955/cbup.v3.611

Keywords: patent, innovation, patenting process

\title{
Introduction
}

The ownership of creations and inventions, resulting from an intellectual or mental effort, is called intellectual property (IP). Intellectual property rights (IPR) protect the interests of creators and inventors by giving them property rights over their creations and inventions. They bestow control over how an IP is used and hold out the prospect of reward, at the same time encouraging further innovation and creativity. There are two distinct branches of IPR: copyright and industrial property rights. Copyright protects artistic creations, such as literature, art, music, sound recordings, films and broadcasts, and computer programs. The branch of industrial property rights comprises of three main protection methods: patents, industrial designs, and trademarks. Patents protect the technical and functional aspects of products and processes. An invention is patentable when it fulfils the criteria of industrial applicability, novelty, inventiveness and patentable subject matter. Commonly, inventors and creators first seek IP protection in their home country. Their first step is normally to file an application at the national patent office. Patent offices are mostly responsible for delivering different types of IPR. Such offices or comparable institutions exist in most countries all over the world. If inventors/creators want to protect their invention in more than one country, they can approach a regional office, e.g. the European Patent Office (EPO) for patents or the Office for Harmonisation in the Internal Market (OHIM) for trademarks and industrial designs. It is also possible to seek IP protection on an international level. In such cases the inventors/creators must contact the World Intellectual Property Organization (WIPO). At the WIPO, it is only possible to apply for patents. The grant procedure will be finalized at a national patent office or at the EPO (Félix, 2007).

\section{The importance of patenting}

There are several reasons why patents are important. Firstly, patents provide incentives to the individuals; in particular, the inventors deserve recognition for their creativity and material reward for their marketable inventions. Secondly, the incentives encourage innovation, which ensures that the quality of human life is enhanced. Thirdly, protection stimulates research, which results in technological development. Fourthly, it enables the inventor(s) to recoup their investment for the money and time spent developing the ideas in Research and Development. Lastly, the use of patent documents enables future researchers not to re-invent the wheel, just to mention a few (Pacra, 2013).

\footnotetext{
${ }^{1}$ Ing. Mário Al Kassiri, Faculty of Operation and Economics of Transport and Communications, University of Žilina, mario.alkassiri@fpedas.uniza.sk

${ }^{2}$ Ing. Tatiana Čorejová, PhD, professor, Faculty of Operation and Economics of Transport and Communications, University of Žilina, tatiana.corejova@fpedas.uniza.sk
} 
It is necessary to determine all aspects of patenting, but most of all it is important to consider whether the protection required is appropriate. Suitability is the meaning of money and time, respectively, whether it is the right time to input the product into market. Many global innovations were brought on very early, or too late; this can pose as a high risk factor for demand of patented product. The timeframe is the primary factor for innovations. Bringing up the innovations for existing ideas, such MP3 players, when a decline in production has been reported earlier is undesireable. In this case, mobile devices are an indirectly competitor of MP3 players. It is, therefore, a very important aspect to come up with a patent on the market at the right time after the demand analyses.

Knowledge is known as human capital which is transferred and applied to practice after research and development. It is long and difficult process, but highly valued which can simplify overall production process. The very idea must be researched in the event that comes to patenting, or any intellectual property, it is output which can have positive impact on the overall economy (Al Kassiri \& Čorejová, 2015).

Many individuals are face with the decision of whether to go into the process of patenting or not. Here are the main factors and advantages of patenting, respectively:

- Competitive position in the market is a very important aspect for the company. Innovation plays an important role in competition with an example of the two giants: Apple vs Samsung. Company, which comes with innovation and patents at first, has a greater impact on the market than a company that benefits only from a historical success.

- Individual or a company may get into greater financial business based on a successful start-up in the case that patent interests the investor. Copyrights are automatically transferred to the investor.

- Patents are increasing the value of individual authors as well as the company or university.

Negative aspects of patents:

- Monopolistic position.

- Too early or too late of a patent introduction may cause unprofitability for the author.

Advantages of patenting for educational institutions:

- job creation - not just for researchers,

- increasing competitiveness for industries through their participation in the project,

- increasing private investment into the research and development,

- increasing works of students/graduates to solve specific and practical problems,

- developed projects are solved with the help of purchased infrastructure financed by public funds (VEGA, sectorial subsidies, etc.); from foreign sources, which are known as characteristic research (Framework Programmes of the European Union for research and development, COST, ERA-NET, Leonardo, etc.); and from private sources, such as contract research,

- output of applied research and development - as a prototype, software prototype, creation methodology/workflow, useful practice, etc.,

- creation of indirect positive effects caused by the existence of a project funded by the OP,

- research and development, such as the creation of spin-off companies, etc.

Figure 1 shows that universities have the largest percentage share of applications. This implies the importance of universities in start-ups and preparing students for innovation in practice. 
CBU INTERNATIONAL CONFERENCE ON INNOVATION, TECHNOLOGY TRANSFER AND EDUCATION

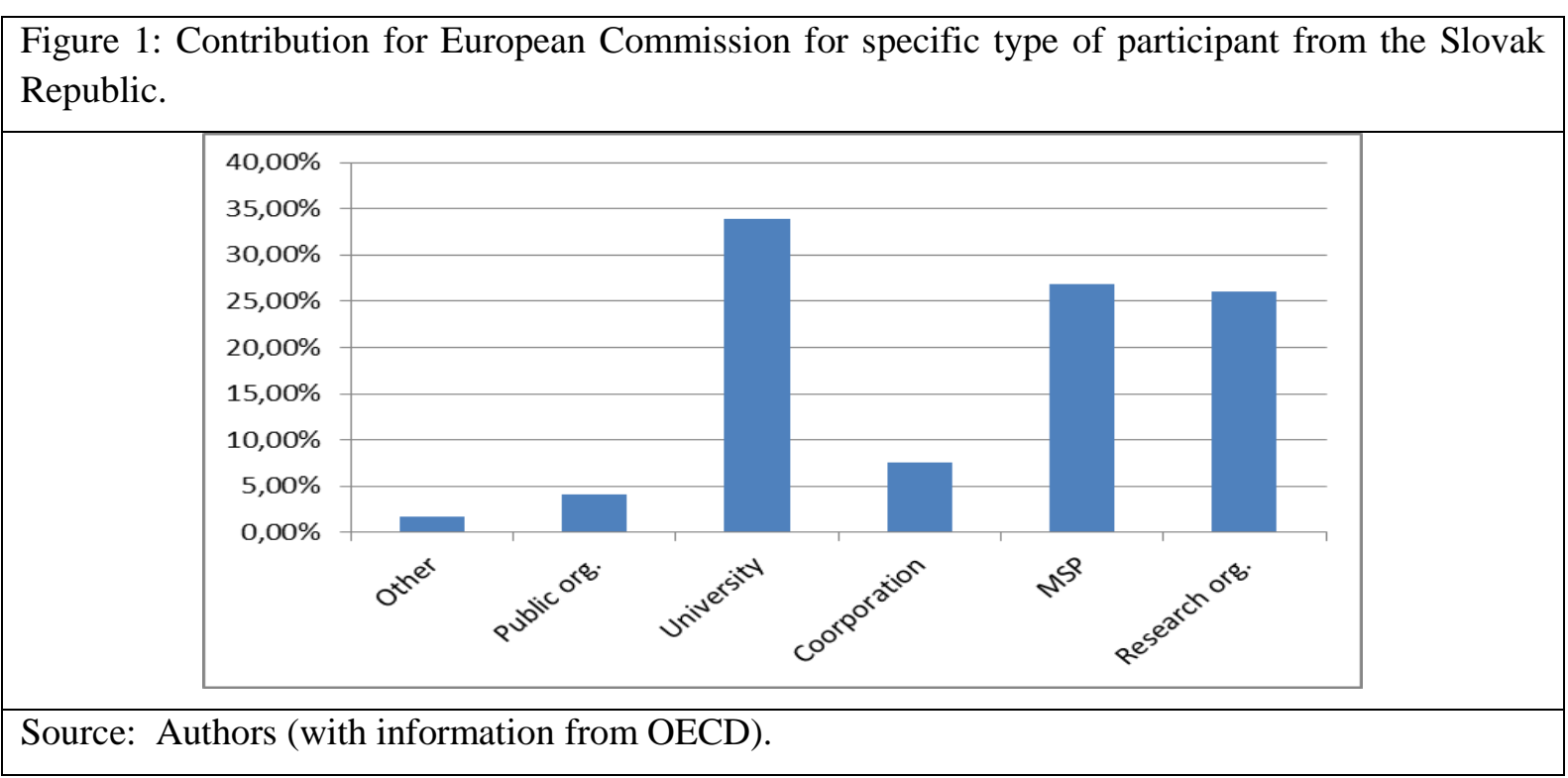

\begin{tabular}{|l|r|r|r|r|r|}
\hline \multicolumn{6}{|c|}{ Table 1: Patents granted in Czech and Slovak Republic between year 2010 and 2014} \\
\hline \multicolumn{1}{|c|}{ Country } & $\mathbf{2 0 1 0}$ & $\mathbf{2 0 1 1}$ & $\mathbf{2 0 1 2}$ & $\mathbf{2 0 1 3}$ & $\mathbf{2 0 1 4}$ \\
\hline Czech republic & 45 & 55 & 56 & 67 & 66 \\
\hline Slovakia & 12 & 3 & 13 & 5 & 11 \\
\hline Czech republic & $79 \%$ & $95 \%$ & $81 \%$ & $93 \%$ & $86 \%$ \\
\hline Slovakia & $21 \%$ & $5 \%$ & $19 \%$ & $7 \%$ & $14 \%$ \\
\hline
\end{tabular}

Source: Authors (with information from annual reports 2010-2014).

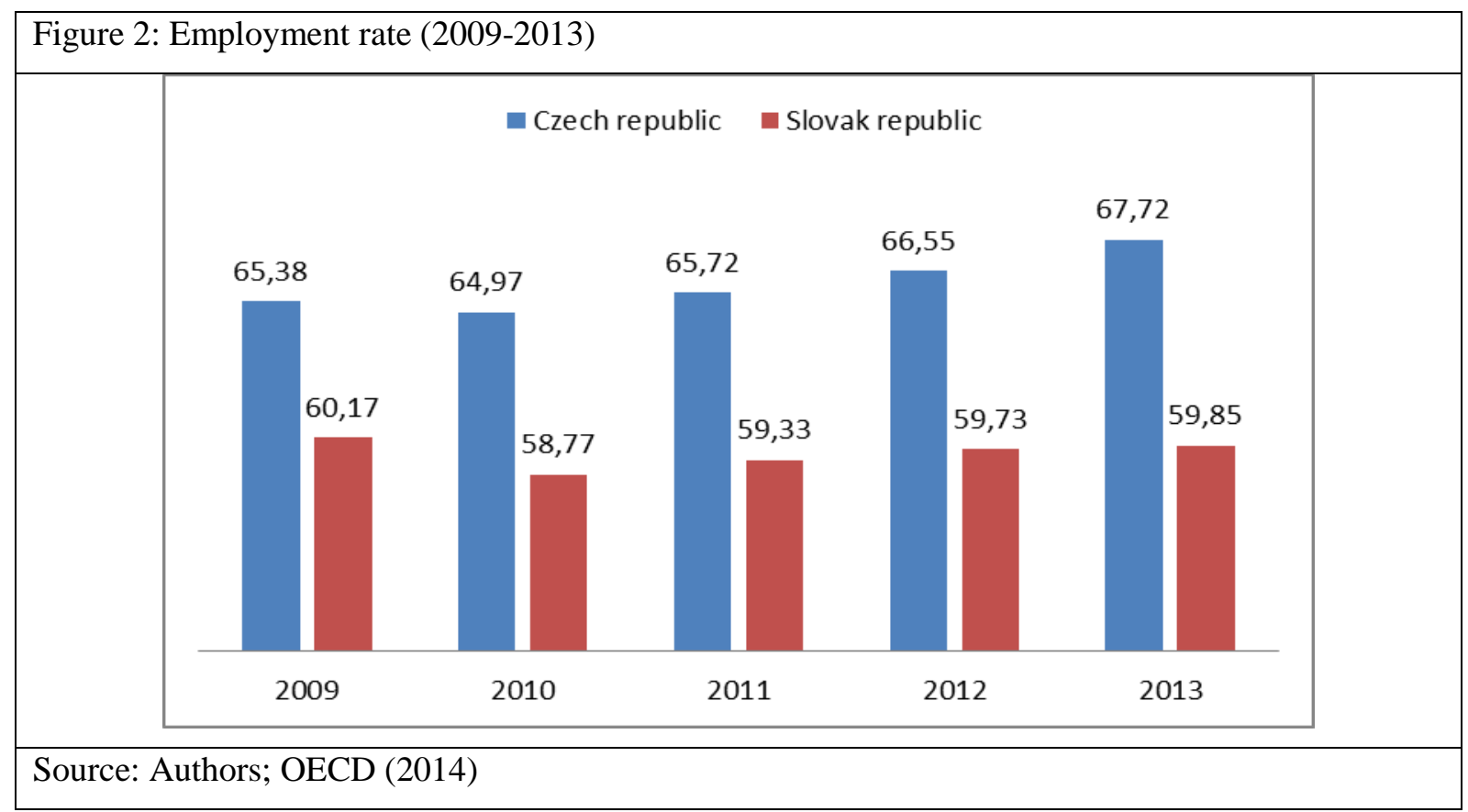




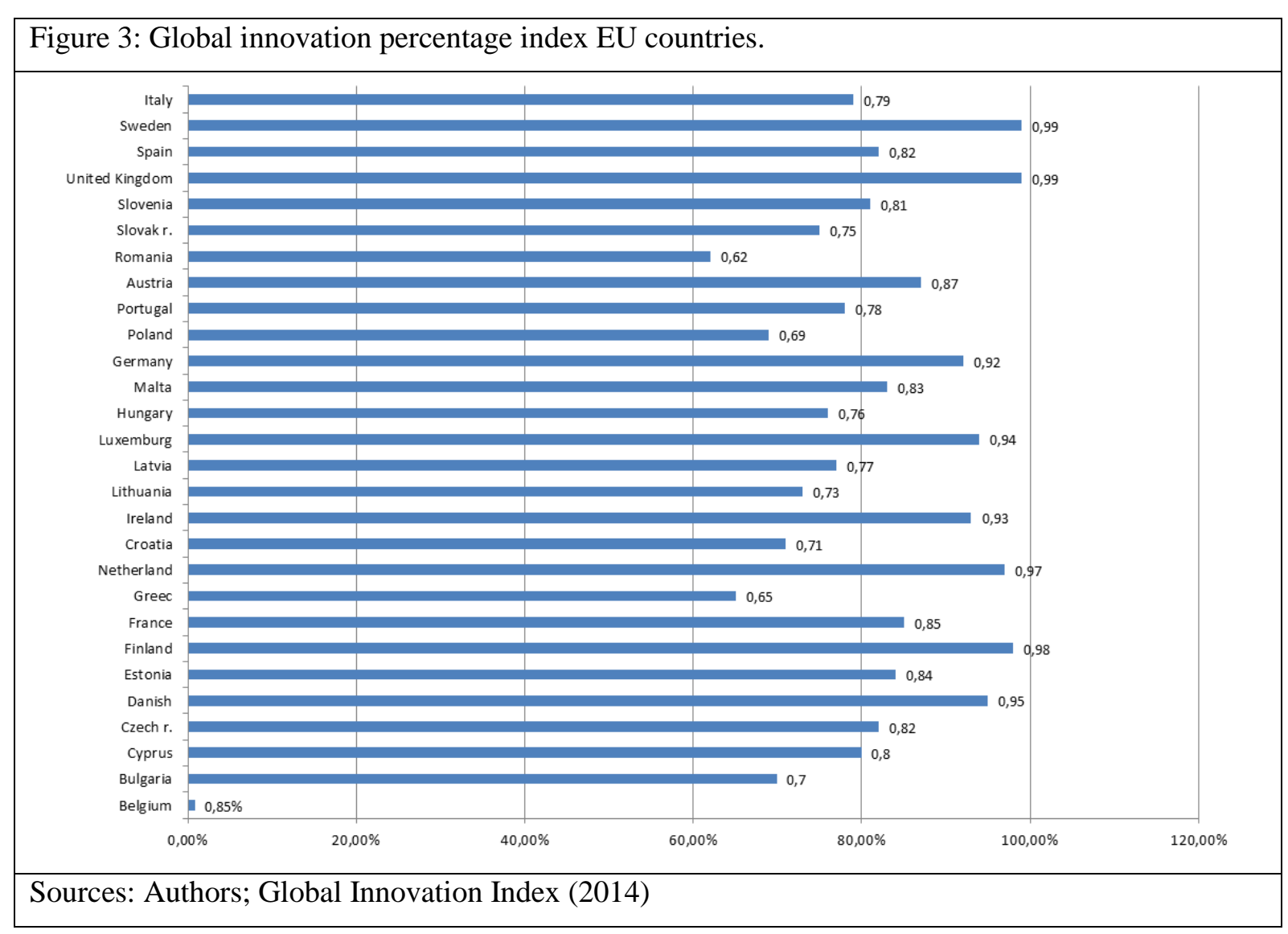

Table 1 shows the total increase/decrease in patents from 2010-2014, where granted patents were mostly increased in Czech Republic, whereas in Slovakia there was a decreasing quantity of patents between 2013 and 2014. There was huge difference in year 2011, where Czech Republic had 95\% more granted patents than Slovakia. This might have had a negative impact on Slovak Republic in terms of employment as shown in the following Figure 2.

Sectors using patent protection are particularly important in terms of employment and contribution to GDP for Czech Republic and Slovakia. As innovations and patents are growing, they have an impact on GDP as well as on employment. Once the start-ups are created, they attract the domestic as well as foreign investors. In turn, this creates the new working opportunities and decreases unemployment. Czech Republic is spending more on research development, which results in more outputs, such as patents and innovations, as well as jobs associated with them.

By December 31, 2013 there were 14,218 valid patents registered in the Slovak Republic; 2,755 of them were granted by a national route; 11,463 were European patents with designati on for the Slovak Republic (Knoth, 2014).

\section{Conclusion}

Patenting is a complex process for implementation as well as financing. For a student who lacks the financial means, the patenting process may not become a reality. But, every year, the number of patents increases, which is caused by the fact that the scope of products are becoming more complicated with demands. Increase in production goes along with innovation of existing or a new type of product. Patent does not only provide an advantage and a strong position in competition, but also a reduction in unemployment for the country. In fact, this happens if the patents can attract investors or can be successfully output by an author himself. Thus, more innovations or granted patents can be considered as an important index for a country. 
University students and graduates play an important role in innovation; therefore, it is necessary to accelerate the similar process. It is important to support innovation projects and projects such as startups. Similarly, projects could also arise directly on the university field, which could act as an extended patent office. A similar project could improve the overall process, facilitates the process of patent offices, and primarily reduces the cost and time spent in patenting. Individual student can complete their research while being directly supervised by a specialist in order to obtain an experience with the research process. University, which sponsors the author of the patent in international exhibitions, may gain not only the profitability, but also the great reputation as it represents the author of the innovation (student). For such exhibition, many other students can be involved in order to gain the experience in whole process - from the process of patenting to the whole marketing process, and to transferring the author's rights. Students mostly choose the university according to its reputation and outputs, which can be research, innovations, and patents. However, it must be also considered that the increase in outputs (patents) increases the university expenditures.

Lastly, knowledge-based economy must be supported. Indirect research has an impact on GDP and employment. Investing in economical knowledge becomes wealth for the country; we can regard knowledge as an inexhaustible resource. A similar case arose at the University STU, where ESET prepares young students for research and practices. Such companies employ hundreds of students all around the world.

\section{The possibility of placing a patent on the market:}

- Providing patent on the global markets (more opportunity to meet with potential investors).

- The possibility of production itself, in the case that the author has investment for the whole process up to its production.

- Another possibility may exist for companies that simply do not want the patent to be produced in order to take advantage of the market positioning.

\section{Acknowledgements}

\section{VEGA - 1/0515/15}

Endogenous factors of the IPR intensive Industries in the regional enterprise environment in Slovak Republic. (01.01.2015 - 31.12.2017)

\section{VEGA - 1/0420/14}

Modern approaches to identification the factors influencing shopping decision makingneuromarketing research using the eye tracking. (01.01.2014-31.12.2016)

\section{References}

Al Kassiri, M., \& Čorejová, T. (2015). The power of knowledge-intensive services. Social Science and Society. Paris: Information Engineering Research Institute, USA.

Félix, B. (2007, May). Innovative enterprises and the use of patents and other intellectual property rights. Retrieved March 2, 2015, from http://ec.europa.eu/eurostat/documents/3433488/5298513/KS-SF-07-091-EN.PDF/3cc14bff-1c37-405c-97045659 f006d623? version $=1.0$

Global Innovation Index, (2014, January). Retrieved March 9, 2015, from https://www.globalinnovationindex.org/ content.aspx?page=data-analysis

Knoth, L. (2014, January 1). Annual report. Retrieved March 7, 2015, from

http://www.indprop.gov.sk/swift_data/source/dokumenty_na_stiahnutie/vyrocne_spravy/AnnualReport_2013.pdf

OECD. (2014, January). Retrieved March 9, 2015, from https://data.oecd.org/emp/employment-rate.htm

Pacra, (2008, February 28). The Importance of patents for Innovation.Zambia. Retrieved September 27, 2015, from www.pacra.org 